\title{
Influence of Wind Generators in Voltage Dips
}

\author{
E. Belenguer ${ }^{1}$, N. Aparicio ${ }^{1}$, J.L. Gandía ${ }^{1}$, S. Añó ${ }^{2}$ \\ ${ }^{1}$ Department of Industrial Engineering and Design \\ Universitat Jaume I \\ Campus de Riu Sec, E-12071 Castelló (Spain) \\ Phone:+34 964 728176, Fax:+34 964 728170, e-mail: aparicio@esid.uji.es, efbeleng@esid.uji.es \\ ${ }^{2}$ Department of Electrical Engineering \\ Universidad Politécnica de Valencia \\ Camino de Vera s/n, E- 46022 Valencia (Spain) \\ Phone: +34 963877007 ext. 75963, e-mail: sanyo@die.upv.es
}

\begin{abstract}
The article deals with the voltage quality problems that wind generation in distribution networks can produce to the loads supplied from the same grid. In order to evaluate and quantify these problems, simulations with the PSCAD/EMTDC software package have been carried out in a simplified model of a distribution network with squirrel cage induction wind turbine generators. The results show that the presence of the wind generators increases the voltage drop and prolongs the duration of a voltage dip.
\end{abstract}

\section{Key words}

Power quality, voltage dips (sags), induction generator, wind energy, fixed speed wind farm.

\section{Introduction}

In 1999, the Spanish Renewable Energy Promotion Plan set a target for wind power of 8,974 MW by 2010 . Due to the fact that at the current time this target has been exceeded, the Spanish government has raised it to 20,155 MW by 2011. Over 2004, the Spanish capacity registered the world's highest growth (38\%) with 2,360 MW. These data have forced to consider wind energy no more as a small fraction of the total electrical energy generation with a reduced influence in the whole electrical system. In certain moments in September $18^{\text {th }} 2005$ more than $30 \%$ of the electrical energy generated in Spain was wind energy.

It is well known that a huge penetration of wind energy in a power system may cause important problems due to the random nature of the wind and the characteristics of the wind generators. In large wind farms connected to the transmission network $(220-400 \mathrm{kV})$ the main technical constraint to take into account is the power system transient stability that could be lost when, for example, a voltage dip causes the switch off of a large number of wind generators.

In the case of smaller installations connected to weak electric grids such as medium voltage distribution networks $(20 \mathrm{kV})$, power quality problems may became a serious concern because of the proximity of the generators to the loads. Flicker emission, harmonics, voltage variations and voltage dips are reported to be the main quality problems [1], [2].

The existence of voltage dips is one of the main disturbances related to power quality in distribution networks. In developed countries, it is known that from $75 \%$ up to $95 \%$ of the industrial sector claims to the electric distribution companies are related to problems originated by this disturbance type. These problems arise from the fact that many electrical loads are not designed to maintain their normal use behaviour during a voltage dip.

Spanish present regulation (1985) establishes that wind generators must be equipped with instantaneous minimum voltage protections that immediately disconnect them when the terminal voltage reaches the $85 \%$ nominal voltage. It is interesting to note that this regulation also requires a minimum short-circuit ratio of 20 and limits the voltage drop to $2 \%$ [3].

To avoid a generalized switch-off in the case of the presence of a voltage dip in the system, network operators in many countries are requiring wind farms to have fault ride-through capabilities [4], [5]. Figure 1 shows a typical undervoltage relay characteristic having an inverse voltage-time response.

Red Eléctrica de España (REE), the Spanish Transmission System Operator (TSO), has proposed a draft of Operational Procedure PO 12.3 which includes the requirements for new wind farms and both active and reactive power consumption during and after faults.

For distribution networks with disperse wind generation having instantaneous voltage relays, the presence of a voltage dip will probably cause the disconnection of the generators but, if these are provided with a dip ridethrough system [6], [7], then the transient behaviour of the generator during the voltage dip and subsequent recovery process may affect the voltage waveform prolong- 
ing the duration of the disturbance and increasing the voltage drop. Consequently, the impact of voltage dips in sensitive loads supplied from the distribution network could be increased.

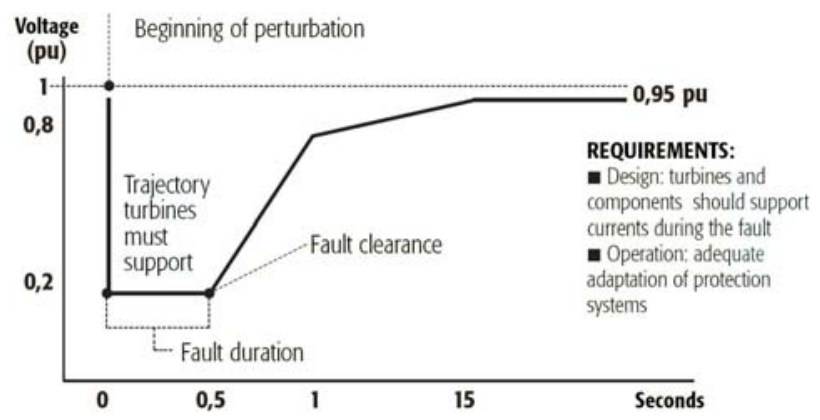

Fig.1. Voltage-time curve admissible at connection point

The behaviour of a wind generator with respect to voltage dips depends on its technology. The main generator types used in current systems are the following:

- $\quad$ Squirrel cage induction generator (fixed speed).

- Doubly fed induction generator (DFIG) with back-to-back converters in the rotor circuit.

- Synchronous (or induction) generator connected through back-to-back converters.

In the case of an induction generator, the presence of a voltage dip causes, initially, a decrease in the active power supplied to the grid and, consequently, an increase in the rotor speed. Similarly, the reactive power consumed by the machine is reduced in accordance to the demagnetization of the generator. When the voltage recovers, the main effect is the absorption of reactive power in order to recover the magnetic flux, extending the duration of the voltage dip [8]. This phenomenon can be of the same magnitude or more severe than a direct machine start-up.

In the work presented in this paper, a simplified model of a distribution network with wind generation has been defined and simulated in order to evaluate the influence of wind induction generators in the magnification of the voltage dips present in the distribution system. Although line-to-ground faults are the most probable type of faults and different simulations have been carried out considering different types of short-circuits, the results shown in the paper are only for balanced disturbances as these constitute the most severe situation.

\section{Objectives}

The objectives of the work are:

- Analyse the behaviour of wind induction generators during a voltage dip evaluating the increase of reactive power consumed by the machine during voltage recovery.

- Quantify the voltage drop increase and time amplification of voltage dips produced in distribu- tion networks due to the influence of wind induction generators.

- Analyse the impact of the wind farm in the voltage quality of the loads connected to a distribution network with wind generation.

\section{Distribution network model with wind generation}

The grid shown in figure 2 has been modelled using standard components from PSCAD/EMTDC software package. The objective is to simulate a typical rural distribution system with overhead lines. The transmission system is represented by a $220 \mathrm{kV}$ voltage source with a $24.2 \Omega$ reactance (2000 short-circuit MVA) while the $\mathrm{HV} / \mathrm{MV}$ substation is composed of a 20 MVA transformer.

The HV/MV substation supplies three feeders as shown in the figure. The resistance and reactance of all the distribution lines are $0.3 \Omega / \mathrm{km}$ and $0.4 \Omega / \mathrm{km}$ respectively. Customers supplied by the distribution network are clustered in eight constant power loads with the same 0.8 lagging power factor.

A wind farm with five generators is connected to the end point of feeder 2. Wind turbine generators are $1.3 \mathrm{MW}$ squirrel cage induction machines with the characteristics shown in Table I. Wind speed is considered constant with the same value $(14 \mathrm{~m} / \mathrm{sec})$ for all wind turbines.

TABLE I. Squirrel cage induction generators p.u. parameters

\begin{tabular}{|c|c|c|c|c|}
\hline $\mathrm{R}_{\mathrm{s}}$ & $\mathrm{X}_{\mathrm{s}}$ & $\mathrm{X}_{\mathrm{m}}$ & $\mathrm{R}_{\mathrm{r}}$ & $\mathrm{X}_{\mathrm{r}}$ \\
\hline 0.066 & 0.046 & 3.86 & 0.018 & 0.122 \\
\hline
\end{tabular}

Real wind farms with this kind of generators are equipped with capacitor banks in order to partially compensate the reactive power consumed by the machine. However, in the model employed in this work, capacitors have been avoided so the reactive power is supplied by the transmission system.

Voltage dips are mainly caused by faults (short-circuits). In a distribution system, voltage dips may have a double origin, internal or external. In order to analyse the influence of the proximity between the fault and the generators, two different cases, according to the origin of the fault, have been considered:

- CASE 1. The fault is located in the HV grid producing a voltage dip that spreads over the distribution network. The dip has been programmed in the HV voltage source with a duration of $200 \mathrm{msec}$ and a voltage drop of the $50 \%$.

- CASE 2. A three-phase short-circuit is simulated in feeder 3 between buses 1 and 9 as shown in figure 1 with a duration of $150 \mathrm{msec}$. Until the circuit breaker opens this feeder, a voltage dip is present in the other two feeders. 


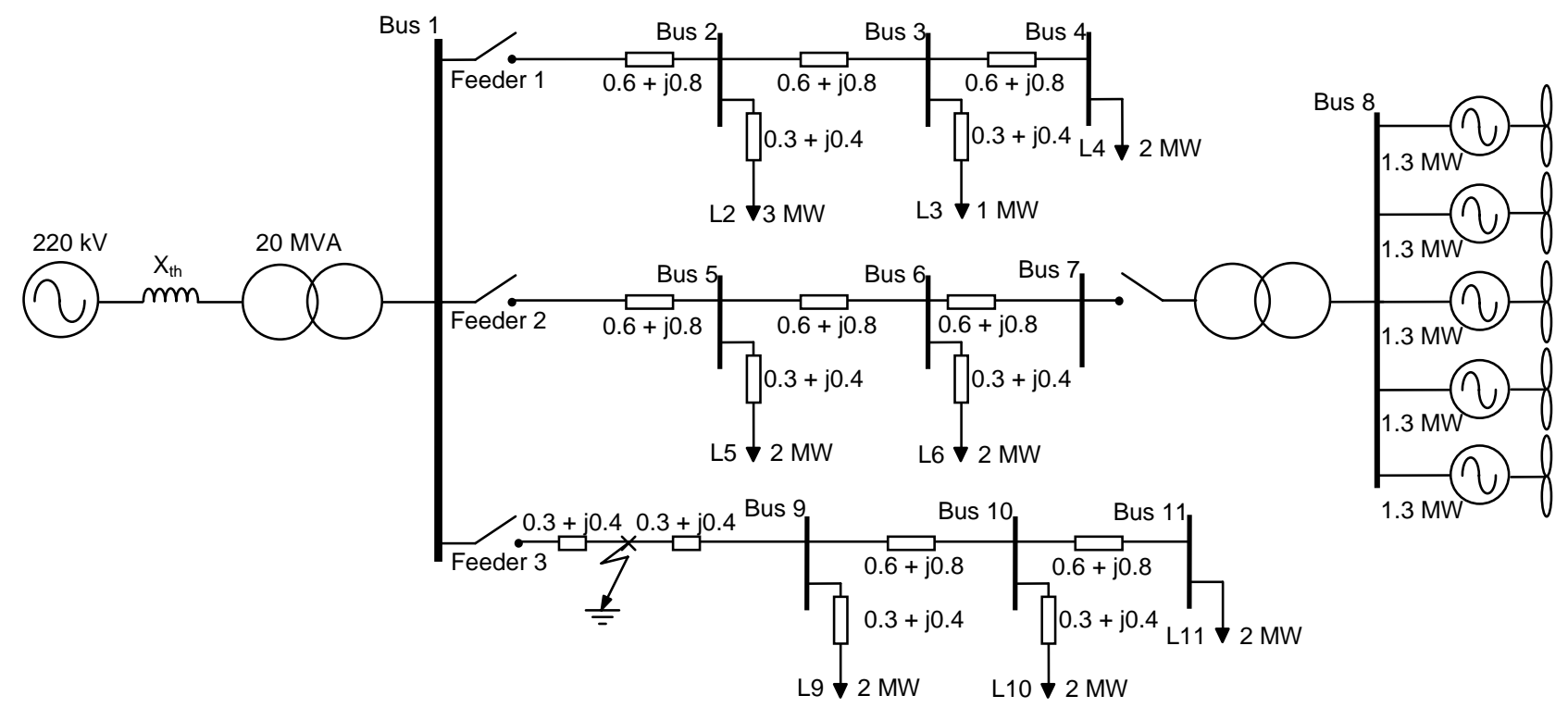

Fig.2. Distribution network model

\section{Results}

For case 1, figures 3 and 4 show the behaviour of the induction generators during the disturbance and the consequent recovery process. Figure 3 shows the real and reactive power in one generator while figure 4 displays its angular speed and the shape of the internal electromagnetical torque. The voltage dip initiates at $0.3 \mathrm{sec}$. producing an instant reduction in both the real power provided to the grid and the electromagnetic torque. As the mechanical torque can be considered constant during this process (mechanical dynamics are neglected because of the short duration of the disturbance), the reduction in the electromagnetic torque produces a significant rotor speed increase as shown in figure 4 .

Once the fault is cleared, the machine absorbs reactive power in order to recover its magnetic flux, with an initial peak value more than three times higher than its nominal value. After the peak, the generator continues consuming high values of reactive power for almost a second, extending the phenomenon duration.

The impact of this behaviour in the network can be seen in figure 5. Voltages are shown for different nodes at feeders 1 and 2. As expected, the higher voltage drops are produced in feeder 2 (with the wind generators) although similar effects can be seen in feeder 1 (loads L2, L3 and L4) and feeder 3 (not shown in the figure).

To quantify the influence of the wind generation in the drop and duration of voltage dips, figure 6 shows the voltage in bus 7 (connection point with the wind farm) with and without the wind generation.

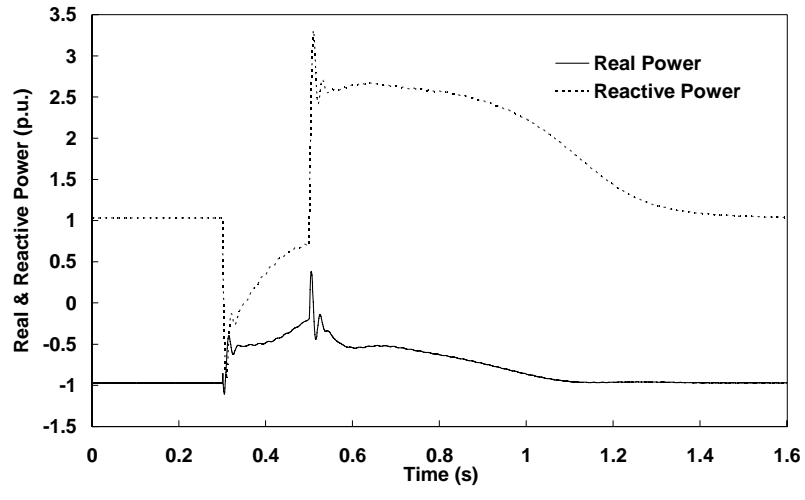

Fig.3. Generator real and reactive power

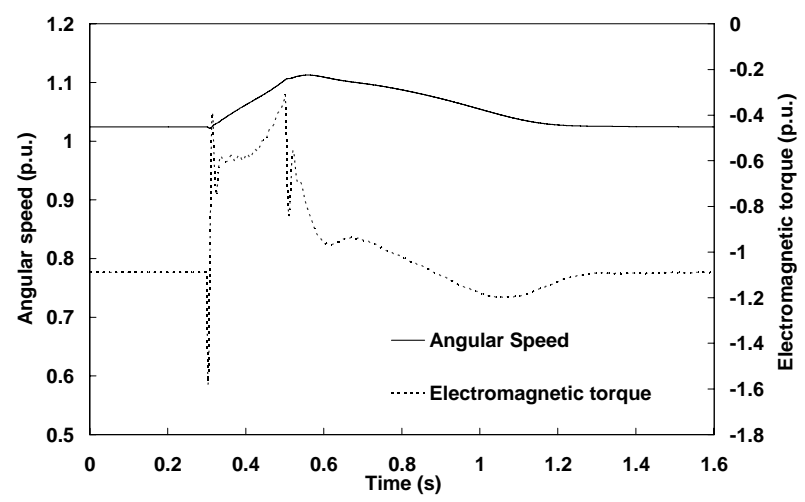

Fig.4. Generator angular speed and electromagnetic torque 

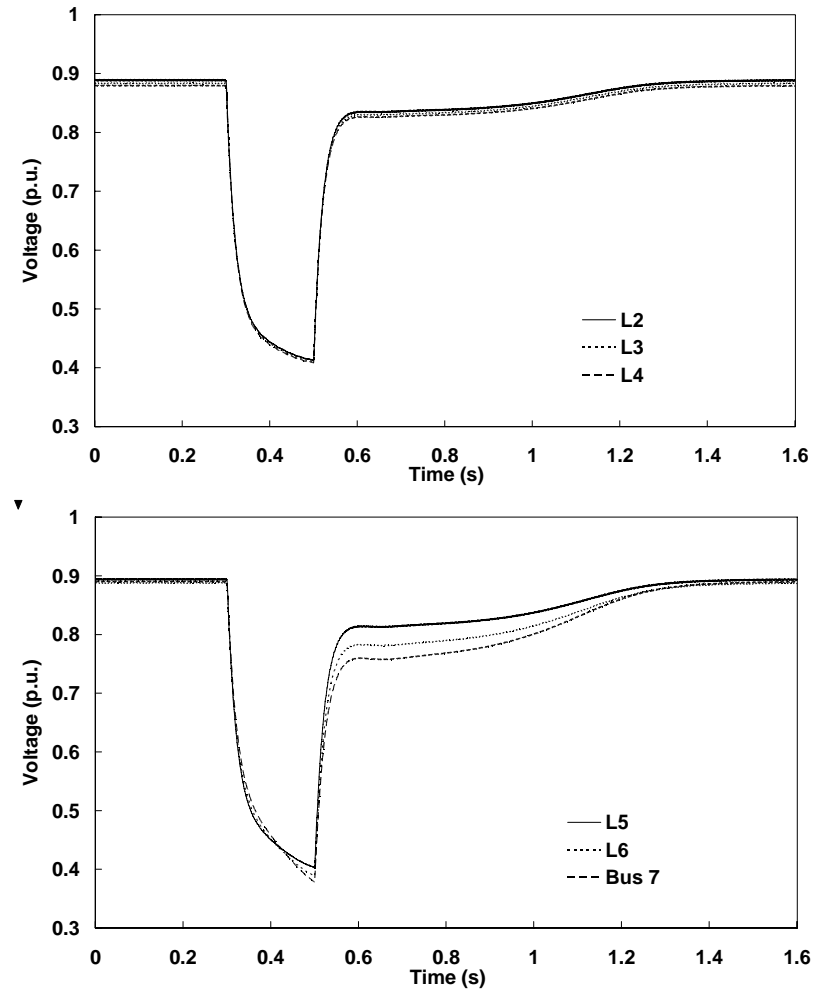

Fig.5. Voltage dip in feeders 1 and 2 for case 1

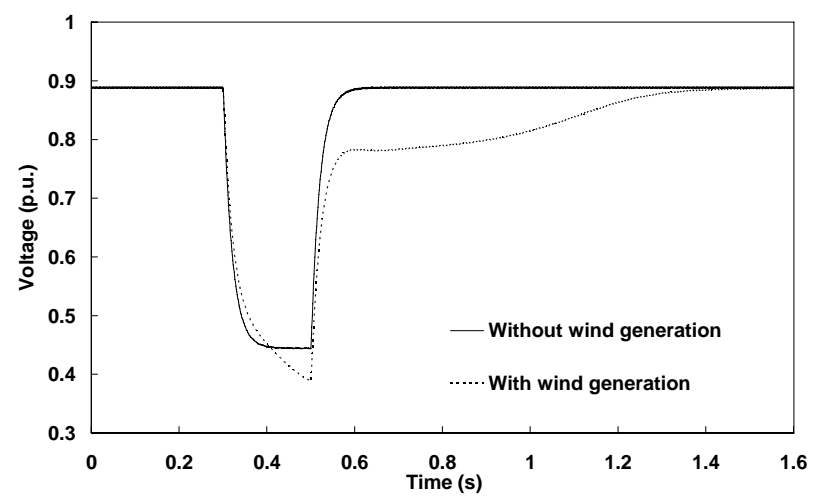

Fig.6. Amplification of the voltage dip in case 1

It can be seen from figure 6 that the maximum voltage drop has an increase of about the $7 \%$ due to the wind generators and, what is more important, that the voltage dip is prolonged for several times the duration of the dip with voltage drops up to $10 \%$ the nominal value.

Similar results are obtained for case 2 as shown in figures 7 and 8. As the short-circuit is produced in the same grid the voltage drop is higher in this case. The reactive power peak consumed by the generator is 3 times the nominal value (similar to case 1) but as the demagnetization of the machines is higher in this case, the machines need more time to recover the normal operation (figure 8).
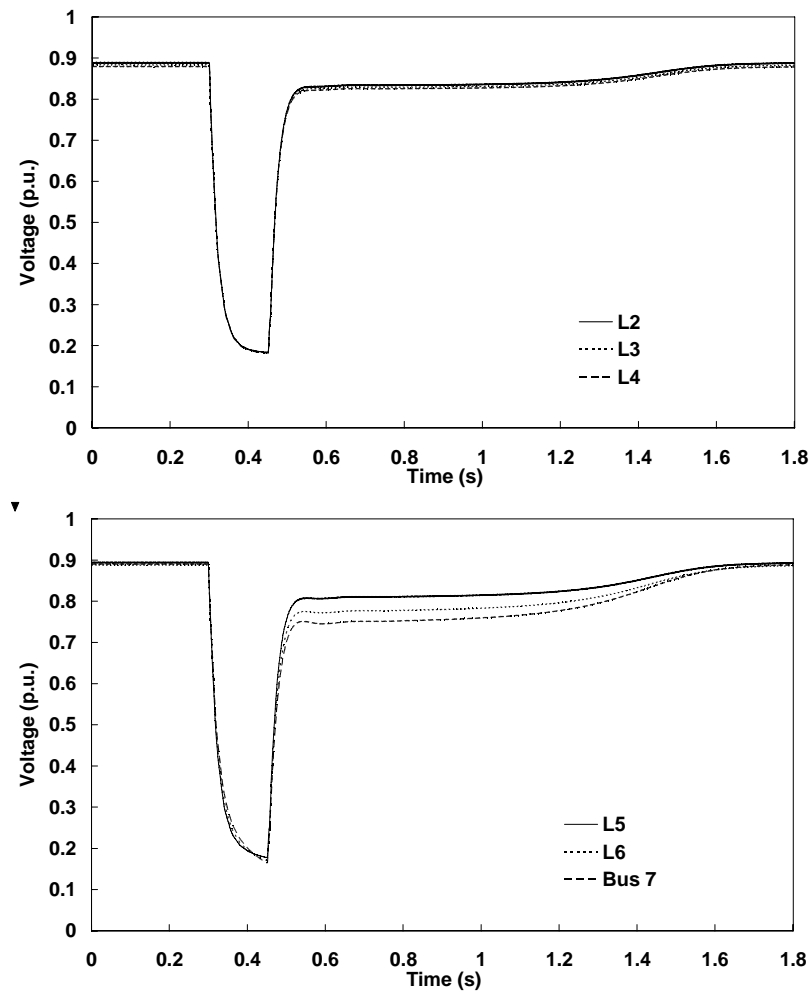

Fig.7. Voltage dip in feeders 1 and 2 for case 2

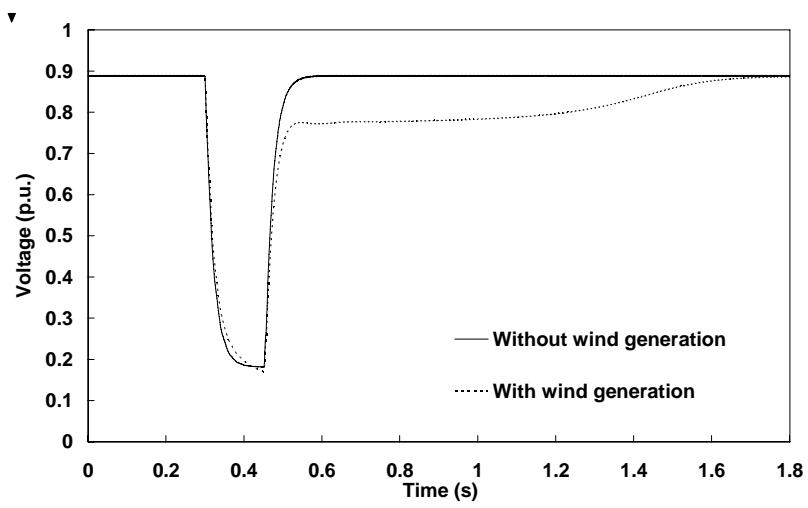

Fig.8. Amplification of the voltage dip in case 2

\section{Conclusions}

From the results obtained in the simulation analysis the following conclusions can be drawn:

- The reactive power peak absorbed from the induction generators during the recovery process (after the voltage dip) can reach from two up to three times the nominal value.

- The time duration of the phenomenon is prolonged from 4 to 6 times the dip time length.

- The maximum voltage drop during the voltage dip can be increased up to a $7 \%$ in the most affected node. During the recovery process, the voltage drop can be increased in a $10 \%$. 
As a result of the previous data it can be said that the voltage quality in a distribution network, with respect to voltage dips, can be significantly reduced due to the influence of wind generation in the same grid. Some sensitive loads connected to the same distribution network would not stand the new voltage profile.

It is interesting to note that the obtained results can help in the definition of an adequate undervoltage protection system for wind generators connected to distribution networks.

\section{References}

[1] J. O. G. Tande, "Grid Integration of Wind Farms", Wind Energy, Vol. 6, No. 3, pp 281 - 295, June 2003

[2] M. H. J. Bollen, G. Olguin, M. Martins, "Voltage Dips at the Terminals of Wind Power Installations", Wind Energy, Vol. 8, No. 3, pp 307-318, July 2005.

[3] Boletín Oficial del Estado, No. 219, September 1985.

[4] E.ON Netz GmbH, "Grid Code. High and extra high voltage", Bayreuth, Germany, August 2003 [Online]. Available: http://www.eon-netz.com

[5] Elkraft System and Eltra, "Wind Turbines Connected to Grids with Voltages above $100 \mathrm{kV}$. Technical regulation for the properties and regulation of wind turbines", Denmark, November 2004 [Online]. Available: http://www.eltra.dk

[6] P. Bousseau, F. Fesquet, R. Belhomme, S. Nguefeu, T. C. Thai, "Solutions for the Grid Integration of Wind Farms - A Survey", European Wind Energy Conference, London, November 2004.

[7] A. Petersson, S. Lundberg, T. Thiringer, "A DFIG Wind Turbine Ride-through System. Influence on the Energy Production", Wind Energy, Vol. 8, No. 3, pp 251-263, July 2005.

[8] P. Ledesma, J. Usaola, "Minimum Voltage Protections in Fixed Speed Wind Farms", European Wind Energy Conference, Copenhagen, July 2001. 